\title{
Análise das Preferências dos Estudantes no uso de Videoaulas: Uma experiência na Educação a Distância
}

\author{
Silvia C. Dotta ${ }^{1}$, Erica F.C. Jorge ${ }^{1}$, Edson P. Pimentel, Juliana C. Braga \\ ${ }^{1}$ Universidade Federal do ABC (UFABC) \\ Centro de Matemática Computação e Cognição (CMCC) \\ Santo André - SP - Brasil \\ silvia.dotta@ufabc.edu.br, ericafcj@gmail.com, \\ \{edson.pimentel, juliana.braga\} aufabc.edu.br
}

\begin{abstract}
The production of video lessons and their integration as a tool for teaching and learning is not trivial due to the multiple elements involved especially issues related to visual language. This article aims to analyze the preferences of students by using video classes in a course conducted in Distance Education. The experience is part of a project at a public university in São Paulo whose main objective is to encourage the use of New Information and Communication Technologies (NICT) in the mediation of education in order to assess the results and evaluate the possibility of expanding the proposal. The analysis assumes the problematization of gender video classes, their characteristics and appropriate language for learning.
\end{abstract}

Resumo. A produção de videoaulas e sua inserção como instrumento para o ensino-aprendizagem não é algo trivial devido aos múltiplos elementos envolvidos especialmente questões relacionadas à linguagem visual. Este artigo tem por objetivo analisar as preferências dos estudantes no uso de videoaulas numa disciplina conduzida na modalidade a distância. A experiencia faz parte de um projeto piloto de uma universidade pública de São Paulo cujo objetivo principal é incentivar o uso das Novas Tecnologias da Informação e Comunicação (NTICS) na mediação da educação a fim de avaliar os resultados e verificar a possibilidade de expansão da proposta. A análise pressupõe a problematização do gênero videoaulas, suas características e linguagens adequadas ao aprendizado.

\section{Introdução}

O campo educacional, particularmente, tem ganhado novos contornos a partir do incremento das inovações das telecomunicações e da informática, sobretudo, nas últimas décadas. Segundo Lévy (1998), a técnica é uma das dimensões fundamentais do homem, permitindo que ele atue sobre seu mundo transformando-o constantemente. $\mathrm{O}$ uso refinado das várias técnicas informacionais incidiu sobre o campo educacional e aumentou as possibilidades de interação entre o sujeito aprendiz e o conteúdo.

Esse caminho de transformação que a educação vem percorrendo coloca todos os envolvidos (professores, alunos, coordenadores e outros) em uma posição de reflexão sobre seus papeis, sobre suas atuações. Se antes o professor centralizava o conhecimento em sua figura, hoje, o acesso facilitado que as várias mídias permitem, fazem com que alunos possam tomar contato com diversos conteúdos muito antes deles serem apresentados em sala de aula presencial ou virtual. O professor deixa, portanto, 
de assumir a educação para si e tem seu papel deslocado para o de facilitador de conhecimentos, uma pessoa que vai conduzir a aprendizagem. Saímos do paradigma transmissivo para uma educação não diretiva [Snyders, 1978] ou dialógica [Dotta, 2009]. Já os alunos, saem de uma posição receptiva e passam a ter a oportunidade de atuar ativamente em sua aprendizagem, vide os vários trabalhos sobre a necessidade de autonomia e responsabilidade exigida dos alunos, principalmente dos que optam por cursos a distância [Martins, 2002; Bezerra e Carvalho, 2011].

Muitos teóricos da educação já se debruçaram longamente sobre a revisão do papel do professor e dos alunos [Niskier, 1999; Oliveira, 2003] a partir do uso das novas tecnologias no ensino. Cabe aqui a reflexão específica sobre o uso das videoaulas, as quais não são materiais recentes para aprendizagem como, por exemplo, a webconferência [Garonce, 2009; Dotta E Jorge, 2011; Dotta et al.,2012].

Apesar de não ser uma tecnologia recente, o que se coloca em discussão nesse artigo é como trabalhar com videoaulas de forma a torná-las mais atrativas para os alunos. O desafio é pensar em linguagens específicas para que, ao assistir uma videoaula, o aluno possa entrar em contato com o conteúdo de uma determinada disciplina, entendendo e sentindo-se atraído pela forma com que foi veiculado.

Os desafios para a produção da videoaula deixam de ser apenas da ordem dos conteúdos, sendo fundamental pensar nas estratégias didáticas. Almeida (2011), seguindo esta abordagem, afirma que até o momento a EaD esteve centrada em tecnologias de rádio e televisão, com pouca ênfase na atuação do professor, porém, com as novas tecnologias da informação e comunicação (TICs) novos desafios foram colocados à prática docente e às estratégias de ensino. Não é possível deixarmos à margem o que acontece também aos alunos que, hoje, se veem imersos em uma multiplicidade de dados provenientes de todos os lados, que poucos conseguem revertêlos em informação, tão pouco, em conhecimento [Machado, 2000; Machado, 2004].

Uma desvantagem da videoaula que vem sendo discutida pela literatura refere-se à sua baixa interatividade. Alguns teóricos alegam, inclusive, a impropriedade da terminologia 'mediação pedagógica' para situações educacionais com uso de CDs e DVDs. Apesar dessa discussão, cabe ressaltar que já existem tecnologias disponíveis no mercado que podem aumentar consideravelmente a interação do aluno com as vídeoaulas. Esse é o caso das aulas em que o professor lança uma pergunta e o vídeo para e espera pela resposta do aluno para prosseguir. $\mathrm{O}$ desafio está em tornar essa tecnologia acessível aos educadores.

Oliveira (2001) é uma das autoras que advoga o uso da nomenclatura 'intermediação tecnológica' para videoaulas e não 'mediação pedagógica', uma vez que os sujeitos envolvidos no processo ensino-aprendizagem não estão em ação, em interação, ao contrário, segunda ela, trata-se apenas de uma intermediação por um recurso tecnológico. De todo modo, não se trata aqui de discutir o uso desses conceitos mas, apenas, apresentar as reflexões que vêm sendo feitas sobre o assunto. Cabe ressaltar que as pesquisas sobre videoaulas são, ainda incipientes. Como exemplo, citamos um breve levantamento realizado no banco de periódicos da CAPES. Há apenas 13 artigos que abordam a produção de vídeos em ambientes educacionais, a grande maioria em língua espanhola, entre os anos de 1994 e 2012. Em outros repositórios, como Google acadêmico também foi possível encontrar alguns materiais, mas, quase todos, abordam 
as etapas de pré-produção, produção e pós-produção de vídeos para uso na educação [Spanhol e Spanhol, 2009]. Contrariamente ao que se propõe nesse artigo, o material encontrado levanta mais uma discussão técnica do que didático-pedagógica.

Apesar do importante papel que a videoaula vem tomando na educação, ainda existem poucos relatos de pesquisas sobre o assunto. Esse artigo visa atuar nessa lacuna e produzir insumos para que as discussões teóricas e a aplicação prática das videosaulas possam ser fundamentadas e direcionadas respectivamente. Nesse sentido, o artigo tem por objetivo analisar os dados experimentais sobre as preferências dos estudantes com a inserção de videoaulas numa disciplina de graduação na modalidade a distância.

O artigo está organizado como segue. A seção 2 discorre sobre a produção de vídeoaulas e as possíveis linguagens para ela. A seção 3 caracteriza a produção e o uso de videoaulas para o Ensino de Algoritmos na modalidade a distância A seção 4 apresenta os resultados da avaliação das videoaulas na perspectiva dos estudantes. Por fim, a seção 5 trata das considerações finais e trabalhos futuros.

\title{
2. Produção de videoaulas e suas linguagens
}

Conforme anunciado na seção anterior a literatura acadêmica ainda não é capaz de indicar pistas seguras sobre o estudo das videoaulas. Spanhol e Spanhol (2009) dão importante contribuição para professores que se desafiam a produzir videoaulas. Serafim e Souza (2011) são outras pesquisadoras que estudaram as possibilidades do vídeo digital integradas ao contexto escolar. É talvez com Camargo et al. (2011) que algumas definições específicas sobre videoaulas são apresentadas:

\begin{abstract}
A videoaula é um gênero que claramente absorve características da aula presencial, como a existência de um enunciado expositivo, planejado e muitas vezes apresentado por um professor, com a intenção de levar conhecimento ao aluno em um processo de ensino-aprendizagem. Entretanto, ele traz novas características, como a utilização da mídia audiovisual, a interação assíncrona ou ausência de interação com os alunos, a possível utilização simultânea de várias linguagens visuais que podem ser combinadas com o áudio, etc. [Camargo et al., 2011, p. 5].
\end{abstract}

Pensar sobre produção de videoaulas é, portanto, pensar a prática docente envolta e aberta para novas propostas educacionais. Segundo Serafim e Souza (2011, p. 27) "o preparo dos docentes brasileiros para a utilização de mídias e objetos digitais como materiais didático-pedagógicos ainda é insipiente". No entanto, é justamente acerca deste preparo que os professores precisam refletir, entendendo a videoaula como mais uma alternativa tão eficiente quanto sua prática docente usual. Afinal, as várias tecnologias educacionais facilitam a retenção do conhecimento, "graças à característica reticular e não-linear da multimídia interativa a atitude exploratória [Serafim e Souza, 2011, p. 27].

As videoaulas não são um recurso pedagógico que surgiu recentemente. A partir da década de 1990 com a expansão da tecnologia do DVD e do vídeo digital, houve um maciço uso dos vídeos em educação. A grande vantagem deles era a praticidade do aluno poder assisti-los a qualquer momento e poder revê-los sempre que quisesse ou sentisse necessidade. 
Um dos projetos de grande repercussão midiática foi o Telecurso 2000 [Belloni, 2002]. O padrão das aulas do telecurso era baseado no gênero da telenovela imbricandoo a paradas estratégias para explicação de um determinado conteúdo pedagógico. Tentar reproduzir este modelo pode esbarrar em limites financeiros posto que as aulas eram produzidas com várias equipes, as quais trabalhavam com diversos recursos, equipamentos técnicos, cenários diferenciados, cenas internas e externas, personagens, enfim, a estrutura do Telecurso pode não ser viável para a realidade das instituições educacionais. A ideia é, então, refletir sobre as possibilidades de produção de videoaulas que possam ser planejados e produzidos com recursos acessíveis, discussão esta realizada a seguir com o relato de experiência de um projeto piloto de graduação a distância da disciplina Processamento da Informação.

\section{Videoaulas no Ensino de Algoritmos na modalidade a Distância}

Esta seção tem por finalidade caracterizar a produção e o uso de videoaulas para a execução da disciplina Processamento da Informação (Ensino de Algoritmos) na modalidade a distância, numa experiência piloto com alunos da graduação presencial.

O pressuposto para esse curso piloto foi que os alunos deveriam ter no mínimo os mesmos recursos para a mesma versão da disciplina na modalidade presencial: (a) os conteúdos (slides); (b) explicação dos conteúdos; (d) resposta às dúvidas; (d) correção dos exercícios com comentários(feedback).

Para atender ao item (b) escolheu-se produzir videoaulas, foco desse artigo. Alguns critérios iniciais foram estabelecidos para a padronização na produção das videoaulas, a saber: (i) Elaboração de um padrão estético para todas as videoaulas; (ii) $\mathrm{O}$ rosto do professor deveria aparecer no canto superior da videoaula para buscar uma proximidade ou identificação do professor com o estudante; (iii) As videoaulas deveriam ter a narração do professor para aproximar-se do cenário da sala de aula presencial; (iv) Cada videoaula deveria ter a duração em torno de 20 minutos e nunca extrapolar os 25 minutos.

A figura 1 apresenta o padrão estético adotado para as videoaulas, de forma que os slides deveriam adotar esse padrão e a produção final de cada videoaula.

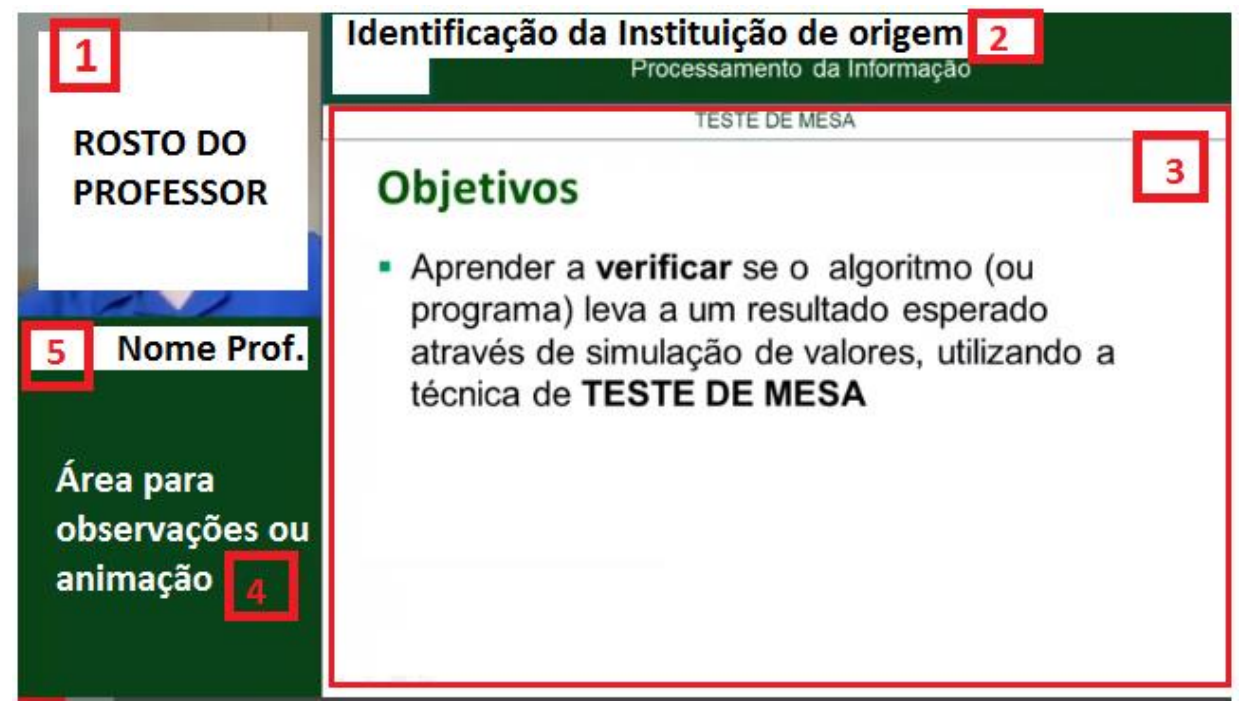

Figura 1. Padrão Estético para a produção das Videoaulas. 
No sentido horário: (1) Rosto do Professor; (2) Identificação da Instituição; (3) Conteúdo abordado com textos; figuras, etc; (4) Área para animação ou observação a partir da narração do professor; (5) Identificação do Professor.

Foram produzidas 42 videoaulas para o curso completo, abordando os seguintes conteúdos da área de Ensino de Algoritmos: (a) Introdução a Algoritmos Computacionais (b) Estruturas de Seleção (c) Estruturas de Repetição (d) Vetores e Matrizes (e) Modularização (f) Ferramentas (tutoriais). Além de videoaulas abordando conteúdos também foram elaborados vídeos adicionais para discussão de solução de exercícios e tutoriais de ferramentas. A tabela 1 apresenta um resumo quantitativo dos videoaulas produzidas.

Tabela 1. Resumo quantitativo das Videoaulas

\begin{tabular}{|l|c|c|}
\hline \multicolumn{1}{|c|}{ CONTEÚDO } & $\begin{array}{c}\text { Videoaulas } \\
\text { (conteúdos) }\end{array}$ & $\begin{array}{c}\text { Videoaulas } \\
\text { (adicional) }\end{array}$ \\
\hline Introdução a Algoritmos Computacionais & 5 & 1 \\
\hline Estruturas de Seleção & 2 & 4 \\
\hline Estruturas de Repetição & 4 & 0 \\
\hline Vetores e Matrizes & 5 & 3 \\
\hline Modularização & 6 & 2 \\
\hline Ferramentas (tutoriais e exemplos) & 1 & 9 \\
\hline & 23 & 19 \\
\hline
\end{tabular}

Cada videoaula relacionada ao ensino de conteúdos apresentava a seguinte sequência didático-pedagógica: (a) Estabelecimento do Objetivo da Aula; (b) Rememoração de pré-requisitos; (c) Abordagem do novo conteúdo a partir de um problema enunciado; (d) Solução do problema enunciado; (e) Novo exemplo e solução; (f) Proposição de Exercícios; (g) Resumo dos principais pontos abordados nas aulas.

Como a instituição não possui ainda um setor completamente estruturado para apoiar a produção de videoaulas grande parte dessas videoaulas de conteúdos (expositivas) foram produzidas utilizando se os seguintes procedimentos:

i. Captura da imagem (via webcam) e áudio do professor (microfone de lapela) durante a projeção dos slides;

ii. Captura da projeção dos slides em cima da narração do professor gravada no passo anterior;

iii. Edição dos itens produzidos nos passos "i" e "ii" sincronizando-os e adicionando elementos de animação.

\section{Avaliação das Videoaulas na Perspectiva dos Estudantes}

A disciplina foi conduzida na Universidade Federal do ABC (UFABC) durante 12 semanas com a participação de 92 alunos. Aconteceram três encontros presencias obrigatórios para a realização da aula inaugural e duas provas. Por ser um projeto piloto para experimentar a educação a distância nos cursos presenciais, envolvendo a criação e sua execução, a disciplina foi acompanhada por 3 professores e 7 tutores. Ao final do curso, $83,7 \%$ obtiveram aprovação e $16,3 \%$ foram reprovados. 
Com o objetivo de avaliar diversos elementos do curso aplicou-se um questionário de avaliação, anônimo, no dia da última prova presencial. As perguntas foram formuladas a fim de se obter elementos para aperfeiçoamento do curso como um todo. Responderam ao questionário 79 estudantes.

Um grupo de questões buscou mensurar a preferência dos estudantes em relação às videoaulas como instrumentos didáticos e os resultados são apresentados a seguir. Em relação às videoaulas foram elaboradas nove perguntas que podem ser categorizadas em três grupos: (a) postura didática do professor nas videoaulas; (b) postura do aluno ao assistir às videoaulas; (c) possibilidades de linguagens para as videoaulas. Os dados analisados nesse trabalho referem-se ao a este último grupo cujas perguntas são apresentadas na tabela 2. Para as respostas utilizou-se a escala de 1 a 5, sendo que " 1 " significa "discordo totalmente" e 5 significa "concordo totalmente".

Tabela 2. Perguntas da Categoria "Linguagens para as videoaulas"

\begin{tabular}{|c|l|l|l|l|l|l|}
\hline \multicolumn{1}{|c|}{ PERGUNTA } & $\begin{array}{c}\text { Discordo } \\
\text { totalmente }\end{array}$ & Discordo & $\begin{array}{c}\text { Nem } \\
\text { concordo } \\
\text { nem } \\
\text { discordo }\end{array}$ & Concordo & $\begin{array}{c}\text { Concordo } \\
\text { Totalmente }\end{array}$ \\
\hline Q1 & $\begin{array}{l}\text { Prefiro vídeos que aparece } \\
\text { SOMENTE a voz do professor. }\end{array}$ & $\begin{array}{l}\text { Tenho preferência por vídeos } \\
\text { em que o professor APARECE } \\
\text { narrando. }\end{array}$ & & & & \\
\hline Q3 & $\begin{array}{l}\text { Aprendi mais facilmente com } \\
\text { os vídeos contendo animações } \\
\text { chamando atenção sobre os } \\
\text { pontos importantes do que os } \\
\text { vídeos mais estáticos. }\end{array}$ & & & & & \\
\hline
\end{tabular}

A figura 2 apresenta o gráfico das respostas da pergunta Q1 em que apenas $12 \%$ (soma de "concordo" e "concordo totalmente") afirmaram que preferem videoaulas que utilizam como recurso de condução da aprendizagem apenas a voz do professor.

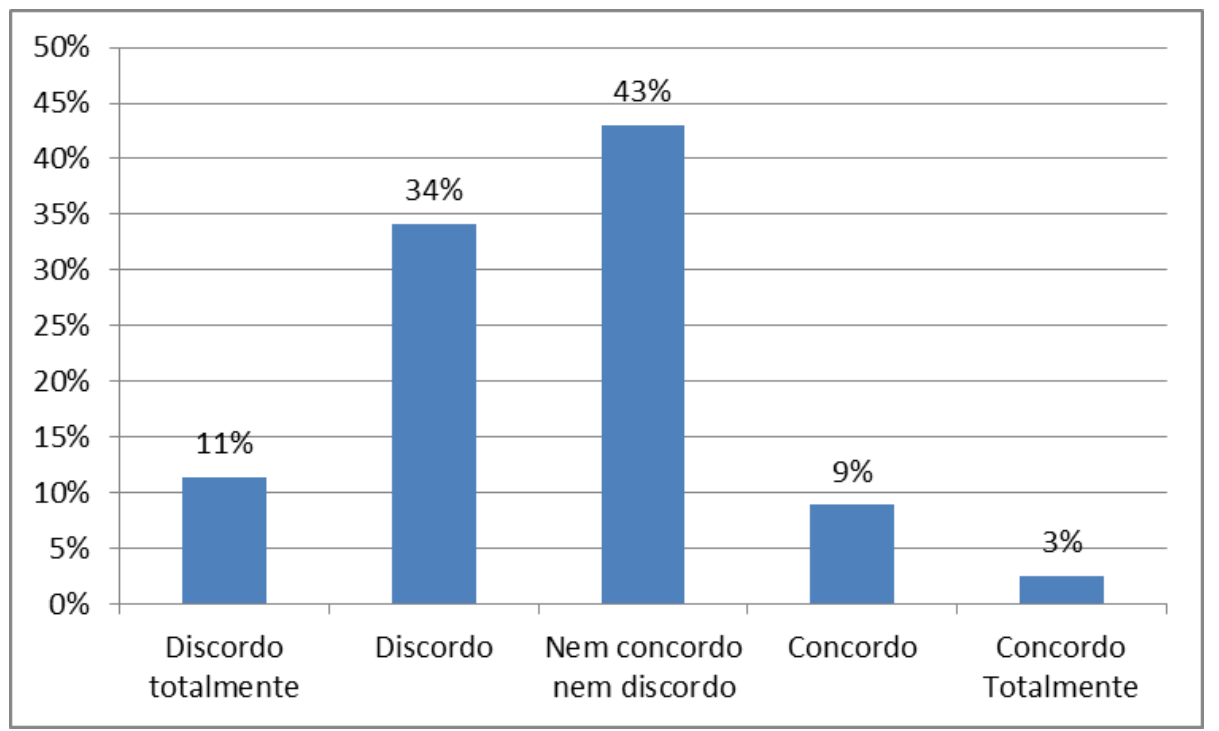

Figura 2. Gráfico das respostas da pergunta Q1: Prefiro vídeos que aparece SOMENTE a voz do professor. 
Apesar de 43\% indicarem que "não concordam/nem discordam" a utilização apenas do recurso sonoro, sem a imagem do professor, ou seja, sem a sensação de estar face-to-face [Recuero, 2009] parece não agradar a maioria dos estudantes, indicando que os mesmos sentem a necessidade da presença do professor virtual [Zuin, 2006]. Mesmo que muitos professores sintam-se inibidos em gravar sua imagem em vídeo o resultado nesse trabalho, indica que para os alunos, somente a escuta do áudio não corresponde às suas preferências.

Esse resultado é confirmado a partir da análise de resultados da questão Q2, sobre a visibilidade do rosto do professor, conforme a figura 3, em que $48 \%$ preferem videoaulas em que os professores aparecem (soma de "concordo" e "concordo totalmente") e apenas $14 \%$ discordam desta preferência (soma de "discordo" e "discordo totalmente"). Mesmo 38\% indicando que "nem concordam e nem discorda", parece que de fato, a imagem do professor, seu rosto, olhares, expressões faciais são relevantes.

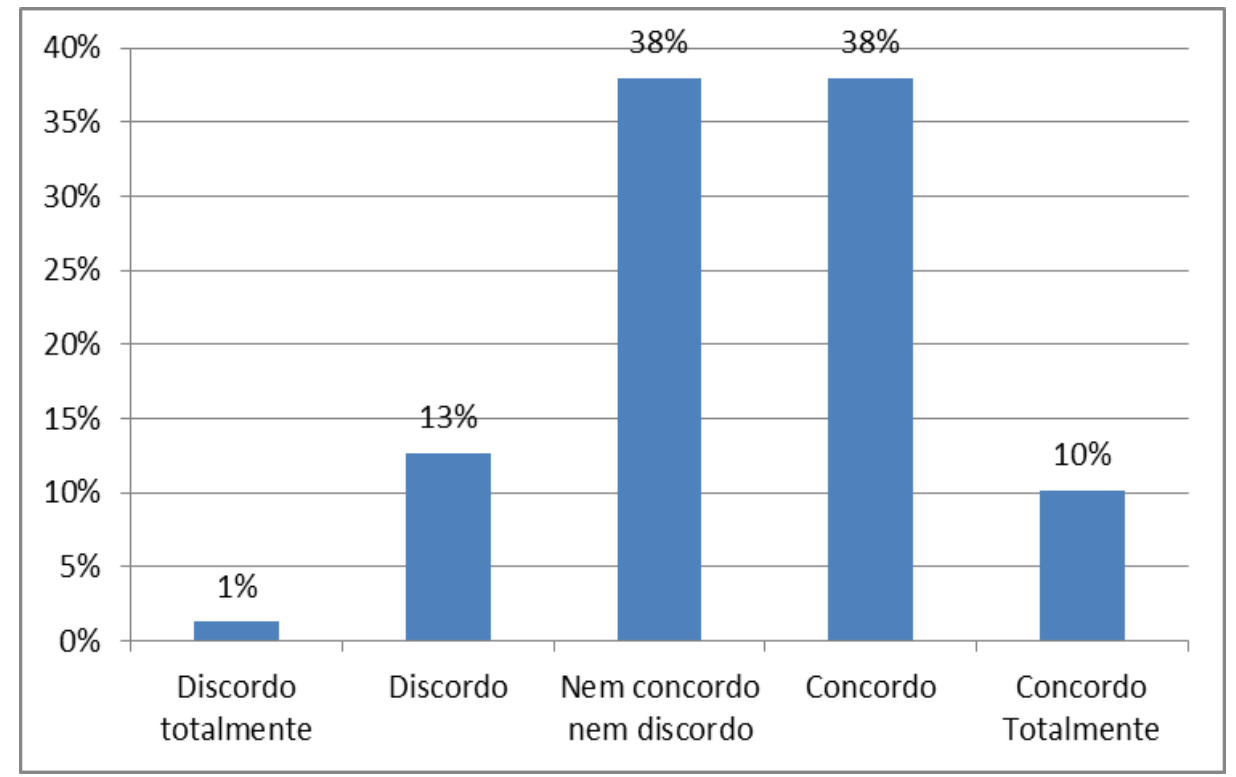

Figura 3. Gráfico das respostas da pergunta Q2: Tenho preferência por vídeos em que o professor APARECE narrando.

Outro dado coletado refere-se à utilização de animações. Algumas videoaulas produzidas continham animações cujo objetivo era chamar a atenção para alguns pontos dos conteúdos discutidos. Perguntados se a aprendizagem foi facilitada por este recurso, conforme mostra a figura 4, 78\% afirmaram que sim (soma de "concordo" e "concordo totalmente") e apenas 5\% afirmaram que não (soma de "discordo" e "discordo totalmente"). A discrepância entre esses números indica que elementos de animação chamam a atenção dos aprendizes, favorecem o aprendizado e o tornam mais atrativo. Essa é, aliás, uma das tendências da EaD, integrar textos escritos, comunicação oral, hipertextual, multimídia [Moran et al., 2000].

As respostas específicas sobre videoaulas obtidas no questionário apontam para decisões importantes ao refletirmos sobre as linguagens para produções das mesmas. $\mathrm{O}$ trabalho de Vialli et al. (2011) atenta que as principais características das videoaulas são o uso de discurso direto e objetivo, a ausência de improvisos e a possibilidade de acesso remoto. A produção de videoaulas para o projeto piloto da disciplina de Processamento 
da Informação a distância indica que outros elementos devem ser pensados. A reflexão em torno da linguagem para videoaulas deve ser ampliada uma vez que alguns desses elementos interferem diretamente no processo de ensino-aprendizagem: o sentimento de pertencimento de uma turma (relação professor-aluno) facilitada pela imagem do professor e o uso de animações e/ou simulações nas videoaulas. Os dados indicam, acima de tudo, a necessidade de problematizar as videoaulas para que aplicações de modelos distintos sejam testados.

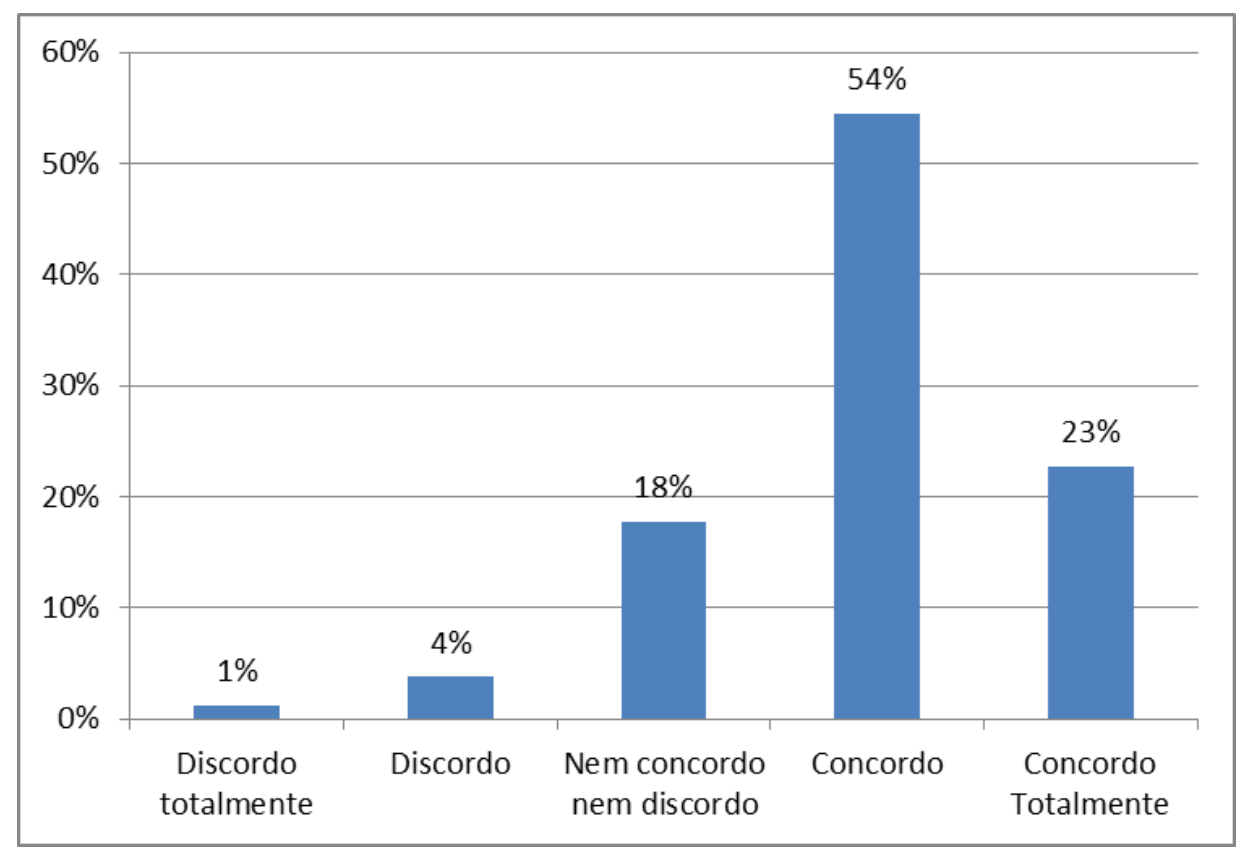

Figura 4. Gráfico das respostas da pergunta Q3: Aprendi mais facilmente com os vídeos com animações chamando atenção sobre os pontos importantes do código do que os vídeos mais estáticos.

\section{Considerações Finais}

Este artigo teve por objetivo analisar as preferências dos estudantes no uso de videoaulas em uma disciplina conduzida na modalidade a distância. A análise foi antecedida pela problematização do gênero videoaulas, suas características e linguagens adequadas ao aprendizado.

A análise foi realizada a partir de um questionário aplicado presencialmente a 79 alunos concentrando-se em 3 questões que discutiam, especialmente, sobre o gênero de videoaulas, tendo por base a necessidade da reflexão sobre as diferentes linguagens das mesmas.

A análise mostrou que os alunos têm predileção pelo aparecimento da imagem do professor no vídeo e não somente a sua narração. Outra preferência detectada na pesquisa é a utilização de animações no vídeo que segundo a maioria dos alunos facilitam o aprendizado. Acredita-se que pelo fato dos alunos estarem separados fisicamente do professor eles prefiram videoaulas com recursos (rosto e animações) que os aproximem do professor. Isso indica que é necessário que os professores, produtores de videoaulas, pensem em mais alternativas que supram essa sensação de distanciamento. No entanto, nem sempre o professor sente-se confortável em expor sua face diante das câmeras e dispõe da tecnologia para realizar essas animações. Isso 
implica que pensar sobre produção de videoaulas é, portanto, repensar a prática docente envolta e aberta para novas propostas educacionais.

Os resultados são uma contribuição para os estudos sobre produções e linguagens de videoaulas, o qual necessariamente precisa ser ampliado e aprofundado a partir de futuros experimentos com produções e aplicações de videoaulas.

\section{Referências Bibliográficas}

Tecnologias da Informação. O futuro do pensamento na era da informática. Trad. Por Carlos Irineu da Costa - Rio de janeiro. Editora 34, 1993. Coleção TRANS. Trad. De'Les techonologies de l'inteligence. $6^{\mathrm{a}}$ reimpressão, 1998.

Almeida, M. E. B. Desafios e possibilidades da atuação docente online. 2011. Disponível em: <www.apropuc.org.br/revistar24_r07.htm>. Acesso em 28 de maio de 2013.

Belloni, M. L. Ensaio sobre educação a distância no Brasil. Educação \& Sociedade, ano XXIII, no 78, Abril/2002.

Bezerra, M. A; Carvalho, A. B. G. "Tutoria: concepções e práticas na educação a distância”. In: SOUSA, R.P., MIOTA, F.M.C.S.C., e CARVALHO, A.B.G., orgs. Tecnologias digitais na educação [online]. Campina Grande: EDUEPB, 2011. 276 p. ISBN 978-85-7879-065-3. Disponível em SciELO Books <http://books.scielo.org>.

Camargo, L.D.V.L; Garofalo, S.; Coura-Sobrinho, J. Migrações da aula presencial para a videoaula: uma análise da alteração de mídium. Sorocaba: Quaestio, v.13, n.2, p.79-91, nov.2011.

Dotta, S. C. Aprendizagem dialógica em serviços de tutoria pela internet: estudo de caso de uma tutora em formação em uma disciplina a distância. Tese de doutorado. São Paulo, Faculdade de Educação da Universidade de São Paulo, 2009.

Dotta, S.C.; Braga, J.C.; Pimentel, E.P.. Condução de aulas síncronas em sistemas de webconferência multimodal e multimídia. In: Congresso Brasileiro de Informática na Educação, 2012, Rio de Janeiro. Anais do Simpósio Brasileiro de Informática na Educação. São Paulo: Sociedade Brasileira de Computação, 2012.

Dotta, S.C.; Jorge, É.F.C. Simulação e Incidência como Estratégias Didáticas na Formação de Tutores para o Uso de Webconferência em EaD. In: $22^{\circ} \mathrm{SBIE}-$ Simpósio Brasileiro de Informática da Educação, 2011, Aracaju, SE. Anais do Simpósio Brasileiro de Informática na Educação. São Paulo: Soc.Bras.Computação, 2011. p. 2091-2100.

Lévy, P. Cibercultura. São Paulo : Ed. 34, 1999.

Garonce, F. V. Os papeis docentes nas situações de webconferência: um estudo de caso acerca da ação educativa presencial conectada. Tese de doutorado. Brasília. Faculdade de Educação. UNB, 2009.

Machado, N. J. Conhecimento e valor. 1. ed. São Paulo: Editora Moderna, 2004. v. 1. $166 \mathrm{p}$.

Machado, N. J. Educação: Projetos e Valores. 4. ed. São Paulo: Escrituras Editora, 2000. v. 1. 160p . 
Martins, A. M. Autonomia e educação: a trajetória de um conceito. Cadernos de Pesquisa, n. 115, p. 207-232, março/ 2002.

Moran, J.M.; MASSETO, M.T.; Behrens, M. A. Novas tecnologias e mediação pedagógica. Campinas: Papirus, 2000.

Niskier, A. Educação a Distância: tecnologia da esperança. São Paulo: Loyola, 1999.

Oliveira, E. G. Educação a Distância na Transição paradigmática. Campinas: Papirus, 2003.

Oliveira, M.R.S.N. Do mito da tecnologia ao paradigma tecnológico; a mediação tecnológica nas práticas didático-pedagógicas. Revista Brasileira de Educação, set./out./nov./dez. $2001, \quad$ n. $18 . \quad$ Disponível em: <http://www.anped.org.br/rbe/rbedigital/RBDE18/RBDE18_10_MARIA_RITA_NE TO_SALES_OLIVEIRA.pdf $>$. Acesso em 28 de maio de 2012.

Recuero, R. Mapeando redes sociais na internet através da conversação mediada pelo computador. In. NASCIMENTO, A.D.;HETKOWSKI, T.M.(Orgs). Educação e contemporaneidade: pesquisas científicas e tecnológicas. Salvador: EDUFBA, 2009, 400 p. ISBN 978-85-232-0565-2. Available from SciELO Books $<$ http://books.scielo.org>

Serafim, M.L.; Souza, R.P. "Multimídia na educação: o vídeo digital integrado ao contexto escolar". In. SOUSA, R.P., MIOTA, F.M.C.S.C., e CARVALHO, A.B.G., orgs. Tecnologias digitais na educação[online]. Campina Grande: EDUEPB, 2011. 276 p. ISBN 978-85-7879-065-3. Disponível em SciELO Books <http://books.scielo.org>.

Snyders, G.. Para onde vão as pedagogias não-diretivas? 2. ed. Lisboa: Moraes, 1978.

Spanhol, G.K.; Spanhol, F.J. Processos de produção de vídeo-aula. CINTED-UFRGS: Novas Tecnologias da Educação, v.7, n.1, 2009.

Vialli, A.; Motta, R.A.; Oliveira, A.; Goldshmidt, R.; Santos, R. Gestão do enriquecimento da elaboração das videoaulas: uma proposta de aumento da interatividade entre professor e estudante. VIII Simpósio de Excelência em Gestão e Tecnologia. Disponível em http://www.aedb.br/seget/artigos11/33114413.pdf Acesso em 02 de agosto de 2013.

Zuin, A. Educação a distância ou educação distante? O programa Universidade Aberta do Brasil, o tutor e o professor virtual. Educ. Soc., Campinas, vol. 27, n. 96 Especial, p. 935-954, out. 2006 